\title{
CORRIGENDUM \\ Factors Associated with Adherence to Transdermal Nicotine Patches within a Smoking Cessation Effectiveness Trial - CORRIGENDUM
}

Jonnie Handschin, Brian Hitsman, Sonja Blazekovic, Anna Veluz-Wilkins, E. Paul Wileyto, Frank T. Leone, Rebecca L. Ashare, and Robert A. Schnoll

doi: 10.1017/S1834261217000020, Published online by Cambridge University Press, 9 March 2017

The above published article by Handschin et al. contains an error in the spelling of an author's name.

Brain Hitsman, should read: Brian Hitsman

This error has now been rectified in the online version of this article.

Handschin, J., Hitsman, B., Blazekovic, S., Veluz-Wilkins, A., Wileyto, P. E., Leone, F. T., et al. (2017). Factors Associated with Adherence to Transdermal Nicotine Patches within a Smoking Cessation Effectiveness Trial. Journal of Smoking Cessation, 1-11. doi:10.1017/jsc.2017.2 